\title{
Regional Styles of Human-Computer Interaction
}

\author{
Clemmensen, Torkil
}

Document Version

Final published version

\section{Published in:}

Proccedings of the 3rd ACM International Conference on Intercultural Collaboration (ICIS), 19-20 August 2010, Copenhagen, Denmark

DOI:

10.1145/1841853.1841891

Publication date:

2010

License

CC BY-NC-ND

Citation for published version (APA):

Clemmensen, T. (2010). Regional Styles of Human-Computer Interaction. In Proccedings of the 3rd ACM International Conference on Intercultural Collaboration (ICIS), 19-20 August 2010, Copenhagen, Denmark (pp. 219-222). Association for Computing Machinery. https://doi.org/10.1145/1841853.1841891

Link to publication in CBS Research Portal

\section{General rights}

Copyright and moral rights for the publications made accessible in the public portal are retained by the authors and/or other copyright owners and it is a condition of accessing publications that users recognise and abide by the legal requirements associated with these rights.

Take down policy

If you believe that this document breaches copyright please contact us (research.lib@cbs.dk) providing details, and we will remove access to the work immediately and investigate your claim. 


\title{
Regional Styles of Human-Computer Interaction
}

\author{
Torkil Clemmensen \\ Department of Informatics, Copenhagen Business School, \\ Howitzvej 60, DK-2000 F, Denmark \\ +4538152389 , \\ tc.inf@cbs.dk
}

\begin{abstract}
This paper draws from Frederic Bartlett's notion that aspects of culture may influence the development of science and technology. Combining additional works from Bloor and research from cultural psychology, we discuss several case (historical and contemporary) studies that illustrate how culture and human-computer interaction are interrelated. These results illustrate how usability problems are tied with global cultures.
\end{abstract}

\section{Author Keywords}

Human-computer interaction, regional design style, organizational design style, design ambiguity.

\section{ACM Classification Keywords}

H.5.2 User Interfaces (D.2.2, H.1.2, I.3.6); Interaction styles (e.g., commands, menus, forms, direct manipulation)

\section{General Terms \\ Design, Human Factors}

\section{INTRODUCTION}

Learning from Bartlett [1] that technology developed in different countries may differ from one another in significant ways related to regional differences in group work style, we argue in this paper that this may also be the case for human-computer interaction. Drawing on arguments from cultural psychology about regional differences in basic psychological processes [2-5], research in social construction of technology that sees a connection between cultural psychology and the development and use of technology [6], information system research on culture and technology acceptance [7], and human computer interaction research about the relation between culture, usability and interaction design [8-11], this paper analyzes examples of regional styles in human-computer interaction. One hand, there may be no impact of technology per se on individuals, groups or organizations, as may be the case with internet technology for virtual teams that rather enhance situation ambiguity and disrupt existing taskartefact cycles. On the other hand, regional differences in group work style does not by themselves cause deep

Permission to make digital or hard copies of all or part of this work for personal or classroom use is granted without fee provided that copies are not made or distributed for profit or commercial advantage and that copies bear this notice and the full citation on the first page. To copy otherwise, or republish, to post on servers or to redistribute to lists, requires prior specific permission and/or a fee.

ICIC10, August 19-20, 2010, Copenhagen, Denmark.

Copyright 2010 ACM 978-1-4503-0108-4/10/08...\$10.00. differences in design of technology, as they are themselves changed by the new technology. As a response to this ambiguity, new national or regional forms of humancomputer interaction may emerge (or are required)[12]. The question is if, with sufficient time and effort, normal style work processes and organizational changes successfully reduce the ambiguity in the relation between the technology and the users - or if the regional forms of human computer interaction sometimes emerge as negative and controversial?

\section{REGIONAL WORK STYLES SHAPE TECHNOLOGY}

Bartlett used the term 'social constructiveness' not only to denote the human ability to construct societies but also to denote the activity in "...which members of a group cooperate to produce some artefact....some product of material arts ...a tool...[which] ...would not exist in the form that it does, or have the identity and meaning that it does, were it not for the traditions and practices of the group who produced it" [6, p194-195]. According to Bloor [6], Bartlett explained technology development with reference to sociological and regional factors.

The case that Bloor discusses is Bartlett's reference to aircraft sound locators build and used during the Great War (WW1). Usually these devices were constructed with two horns listening to the vertical position and two horns listening to the horizontal position of the approaching aircraft. For each position a human operator was required. A third person held sight of the whole instrument. The position was given continuously to a searchlight crew who had the task of trying to capture the airplanes in search lights, and a separate spotter to confirm that this was actually the case. If that was the case, the anti aircraft battery could begin firing. This means that this technology required a large number of men to cooperate. Bloor [6, p206] cites Bartlett for saying (in a draft manuscript for "Remembering" [1]) that "a listening instrument for instance is a group affair, and in the German type the interdependence among members of the listening unit is greater than in the British type". With this, Bloor established that Bartlett argued that regional culture influences technology development.

NEW IT ARTEFACTS ENHANCE SITUATION AMBIGUITY Mantovani [12] argues from a cultural psychology point of view that artefacts have to be considered at the same time both as internal and external worlds, and are both objects of 
our activity (things we create and manipulate), and medium for those activities (things we use to create and manipulate other things with). Using this insight in the field of computer mediated communication, Mantovani [12] argues that the introduction of a new computer artefact creates first usability problems, and then makes the environments into which the artefacts are introduced more difficult to control and more complex. Because social communication is ambiguous, the lack of physical social context in electronic communication makes communication on the internet even more ambiguous. Mantovani suggests that when designing electronic communication, it is important to express a functioning social order in strong and stereotyped form, in order to compensate for the limits associated with electronic communication channels. However, the designers cannot do it alone. The introduction of a new tool in a social context will always a) disrupt people's operational routines, and b) modify the environment, in ways that only can be dissolved with time in individuals', groups' and organizations' daily practice. Mantovani's argument appears to tell us that though group work styles influence the development of technology, it may be equally important to study how the technology influences the work style. Bartlett seemed to put too much emphasis on the human side of the human-technology relation.

\section{THE EXAMPLE OF WORD PROCESSING}

This section discusses the case of the relation between American word processing technology and non-American work style. The examples are from Japan, India, and in particular from Denmark. It is worth spending some time analysing Danish examples, because we may not expect any discrepancies between American technology and the word processing done in Denmark, and the discrepancies found should thus be more surprising and convincing to the reader. The reason for selecting word processing for analysis is that it is the "white rat" of HCI, and much of the founding research term in the field concerned this particular office work task, e.g., [13]. Word processing should thus be a universal technology, with few discrepancies between technology and regional styles of word processing. Furthermore, word processing is a common work activity which has a history going back to the typewriters of the early $18^{\text {th }}$ century, and further back at least to the printable and moveable type at the end of the middle ages [14]. Thus, in this paper, the term "word processing" refers to the work activity involved in e.g., writing papers, reports, letter, emails, etc, and should not be reduced to keyboard input. In the following we do not discuss keyboard limitations, but limitations in the work activities called "word processing".

\section{Japanese word processing}

The first case is how the introduction of the Japanese word processor created a new national style of word processing. Most American word processing software is designed based on the typewrite metaphor. Ito and Nakakoji [15] pointed out that the use of this metaphor is not always successful. In case of the history of the development of Japanese word processors, what happened was that both imported word processors and home-grown systems for word processing, focused on the type writer metaphor, which was a very unfamiliar way to print characters for most Japanese people. First, most people used hand printing up to word processors became available, i.e. typewriters were not common in the Japanese society. Second, Japanese handwriting used to take place within a 20X20 grid and written from top to bottom one column at a time, and right to left. Tap-stops were unfamiliar concepts, and document length was measured in characters and not words. But how would a word processor have looked like had it been developed based on the Japanese writing grid? Of course, now no Japanese would like a different kind of word processor, since they got used to the typewriter-look-alikeword-processor [15].

\section{Indian word processing}

The changes (American) word processing technology may bring about in non latin language cultures may be hard to assess and sometimes surprising. An example is provided by Katre [16] who compares how many keystrokes is necessary to write the same word in different languages and on different mobile phones, see Figure 1. Katre manages to show that in one case it requires 38 (!) key presses to enter a specific sign in Sanskrit on a mobile phone. One can barely imagine how this shape Indian users approach to short text messaging in Sanskrit language. Similar examples can be found in Indian PC word processing [17].

\begin{tabular}{|l|l|l|l|l|l|}
\hline \multicolumn{7}{|c|}{ Nokia 3105 } \\
\hline Devanāgari & म & हा & रा & ष्ट्र & Total number of key-strokes \\
\hline Key-strokes & 5 & 10 & 3 & 18 & 36 \\
\hline Key-strokes & 5 & 9 & 3 & 38 & 55 \\
\hline Key-strokes & 2 & 4 & 4 & 8 & 18 \\
\hline \multicolumn{7}{|c|}{ English spelling of Maharashtratyped using all mobile phones } \\
\hline \multicolumn{7}{|c|}{ Key-strokes } & 20 & 20
\end{tabular}

Figure 1. Typing efforts involved in typing the word Maharashtra on a mobile phone. Reproduced from [16, p9]

\section{Danish word processing}

Word processing was first invented in USA. Countries that are supposed to share cultural values and practices with the USA are western European countries like Denmark. However, there are examples that the design of word processing technology influences the style of word processing not only in Japan and India, but also Denmark. Recently Danish speaking peoples have shown a tendency to go back to archaic forms of the alphabet, used in the Danish language before WW2, in attempts to adapt to imported word processing technology. The examples concerns the use of ae, oe and aa instead of modern Danish $æ, \varnothing$ and å, and include the troublesome use of Danish keyboard layouts on Smartphone text editors, the reduced functionality in terms of spoken dictation for Danish language users of office software, the high technical skills needed to use Danish alphabet on non-Danish computers when travelling outside Denmark, and, not the least, that not before the year 2003 Danish letters were allowed in 
domain names, which for the first time allowed Danish companies like Carlsberg to spell beer on websites in the correct way: "øl".

\section{Smartphones and their impact on Danish writing practices}

Smartphones are also places for word processing and therefore interesting as cases for seeing how a given technology shapes the regional style of word processing. For example there is the case with a Danish blogger who shares his joy of using his new Smartphone, how life has becomes much easier as he now faster can process emails. Among the many input methods he prefer the pc-like keyboard, which however is English, so without æ, ø and å. That means that he has to switch to a Danish language keyboard to key the Danish letters. He does not want to do that, and has developed his own special solution:

"that [to switch to Danish language keyboard] I do not want to waste efforts to do, when I merely want to send a short message. So I practice heavily writing without using words that include æ,ø or å. In fact it is real fun, when you have the positive attitude towards the task. It sharpens the awareness of language when you have to throw away sentences because they include a word that has æ, ø or å in it." [18].

The solution for word processing on smart phones is for some Danish users to adapt the use of the language to avoid words using these letters.

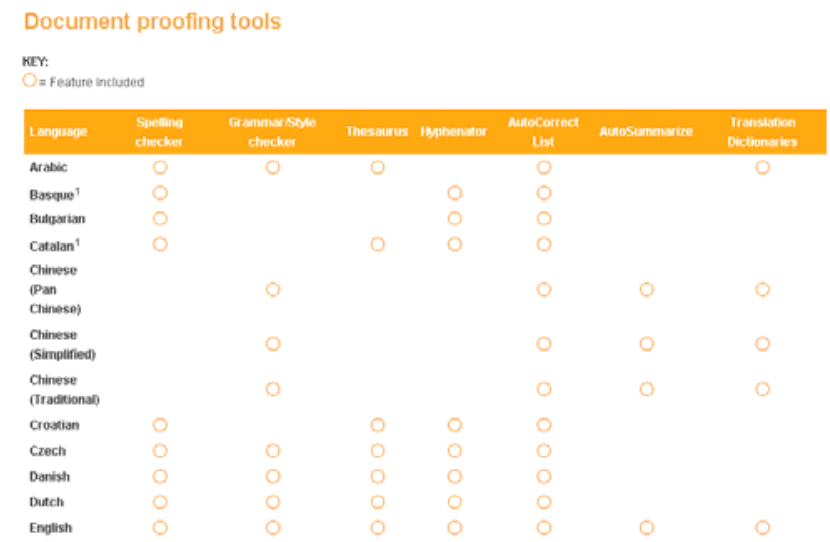

Figure 2. Reduced number of functions in Danish word processing software compared to English language word processing software [19].

\section{Desktop word processing}

For word processors, MS word is widely used in Denmark. Both the user interface and the help system is localised to the Danish language in MS Word 2007 (most recent version at the time of this writing), but Danish language users of MS word is left with a reduced version of the software compared to English language users; the producer gives this information on their website, see Figure 2. What Danish users cannot do is to easily summarize their report by using the software's built in auto summarizing functions. Neither can they get help for translating words from Danish to other languages such as German or English. Furthermore, while it is possible to dictate and edit text by using speech recognition to dictate words into the word processor, this option is only available in English, French, Spanish, German,
Japanese, Simplified Chinese, and Traditional Chinese. While some Danish language users never will discover what they do not get, Danish language users who also write in English may become aware of these limitations in the Danish versions of the word processor.

\section{Un-Danish computers and Danish writing practices}

In a blog on a club for travellers, a Danish traveller Anders Andersen tells the story about what he calls " $Æ, \varnothing$ and $\AA$ on un-Danish computers" [20]. He starts out with the example in Danish "Kaere Aase En lille hilsen fra Oestrig. Haaber du nyder Aegypten..." and use it as an illustration of the fact that most Danish people know these kinds of messages (with oldfashioned writings of $æ, \varnothing$ and å). He then explains (to the readers of this travellers webpage) that it is possible to write $æ, \varnothing$ and å on computers with a keyboard that does not have these letters, by using the numeric code for each letter, through holding down the alt-key while keying the code for the letters, see Figure 3. For example, press and hold "alt" while keying 0230 on the numeric keypad, the letter æ will appear on the screen.

\begin{tabular}{|ccc|}
\hline$æ: 0230$ & $\varnothing: 0248$ & å: 0229 \\
$Æ: 0198$ & $\varnothing: 0216$ & $\AA: 0197$ \\
$@: 064$ & \\
\hline
\end{tabular}

He further writes: “....it may sound al little troublesome, but in fact it is quite easy and after a couple of letters, you will remember these numbers in your head. You will write nearly as fast as when you used ae, oe, and aa, and it does indeed look much better". This is not the whole story; Anders Andersen also explains how to find the alt key and how to make sure that the numeric keyboard is set to be numeric, and not navigation, and why entering zero as the first letter of the code is necessary to make the identification of the letter unambiguous. Andersen's story sounds like a fairytale about a Danish traveller sitting at a Mediterranean internet café and writing letters by punching in numeric codes, struggling with getting the numeric keypad to work. One could ask, what is most old fashioned, using letter-writing forms that were outdated by the Danish language revision in 1948 (made publically available in Retskrivningsordbog udgivet af Dansk Sprogncevn 1955), or punching in codes like punching holes in a punch card? In both cases the impact of technology is that Danish word processing is set back at least 50 years in time. Danish word processing requires more effort than American.

\section{Technology for internet domain names}

Only very recently (in 2003) Danish letters were allowed in domain names, which for the first time allowed Danish companies like Carlsberg to spell beer on websites in the correct way: "øl". This came about with the Implementation of internationalized domain names [21]. The company selling these international domain names announced it like" ...we break the language dominance, and make it possible for 
users to navigate the net no matter what language they prefer to use..." [22]. Besides this new technology created technical issues with browser versions, a user pointed out that by now they were used to the old ways of writing, and would not want to change, Figure 4.

How ridiculous it is to implement things like that. I own a
company "Åberg El", and we have through the past five years
had our website on the following domains:
aaberg-el.com
aaberg-el.dk
aaberg-el.se
aaberg-el.no
These pages are well-known and constantly used by our
customers. ÆEØÅ is introduced as domain names, and
suddenly Åberg-el must invest in the domains: åberg-
el.com,etc...If you do not own both the domain with "aa" and
that with "å", you risk to loose either the old customers or
potential customers. Even worse, a domain shark or a
competitor bought the domain with either "aa" or "å".

Figure 4. Company owner blogging against the use of Danish letters in international domain names[23].

The point is the same as with the Japanese word processor: when users have adapted to a new technology, they do not want changes, even if these would have been welcome when the technology was first introduced.

\section{DISCUSSION AND CONCLUSION}

The conclusion from the discussion above is that there are good reasons to believe that regional work styles and humancomputer interaction are related. However, regional styles in HCI are not static results of social relations, and not simply determined by imported methods or artefacts. Rather time and effort are needed for work processes and organizations to merge, adapt, localize and reduce the ambiguity of the technology. Some cultural psychologists believe that social constructiveness of technology take part as a process with two faces named by Bartlett: conventionalization and schema formation, the first being the outer, observable process, the latter being the inner mental process [24]. As the examples above illustrated in various ways, surely something happens both with users and artefacts across time and use. Not all changes are equally smooth and some changes may be negative and not successful, as the example with the destruction of the traditional Japanese writing style suggested. Others may be contested and controversial, and the Danish use of æ, ø and å in domain names may be a case of that. We must study concrete examples to see how the particular combination of conventionalization and schema formation explains the emergence of regional styles in HCI.

\section{REFERENCES}

1. Bartlett, F. C. Remembering - A study in experimental and social psychology. Cambridge, 1932.

2. Nisbett, R. E., Peng, K. P., Choi, I. and Norenzayan, A. Culture and systems of thought: Holistic versus analytic cognition. Psychological Review, 108, 2 (Apr 2001), 291-310.

3. Hong, Y.-Y. and Mallorie, L. M. A dynamic constructivist approach to culture: Lessons learned from personality psychology. Journal of Research in Personality, 38 (2004), 59-67.
4. Kashima, Y. Culture, Communication and Entitativity - A Social Psychological Investigation of Social Reality. In The psychology of group perception - perceived variability, entitativity and essentialism Edited by V. Yzerbyt, C. M. Judd and O. Corneille.Psychology Press, 2004.

5. Oyserman, D. and Lee, S. W. S. Does culture influence what and how we think? Effects of priming individualism and collectivism. Psychological Bulletin, 134, 2 2008), 311.

6. Bloor, D. Whatever happened to 'social constructiveness'? In Bartlett, Culture \& Cognition Edited by A. Saito.Taylor \& Francis, 2000.

7. Bandyopadhyay, K. and Fraccastoro, K. A. The effect of culture on user acceptance of information technology. Communications of AIS, 2007, 19 (2007), 522-543.

8. Clemmensen, T. Towards a theory of cultural usability: A comparison of ADA and CM-U theory. HCI International 2009 (San Diego, US, (2009).

9. Kurosu, M. Usability and culture as two of the value criteria for evaluation the artifact. Department of Informatics, Copenhagen Business School, 2008. (Working Paper; 01-2008).

10. Dray, S. and Mrazek, D. A day in the life. studying context across cultures. In International User Interfaces Edited by E. del Galdo, \& Nielsen, J.Wiley, 1996.

11.Del Galdo, E. M. and Nielsen, J. International user interfaces. Wiley New York, 1996.

12. Mantovani, G. Internet haze: Why new artifacts can enhance situation ambiguity. Culture and psychology, 8, 3 2002), 307-326.

13. Card, S., Moran, T. P. and Newell, A. The Psychology of HumanComputer Interaction. Hillsdale, NJ: LEA., 1983.

14.Kunde, B. A Brief History of Word Processing (Through 1986) 1986.http://www.stanford.edu/ bkunde/fbpress/articles/wdprhist.html\#PU. 10 may 2010

15.Ito, M. and Nakakoji, K. Impact of culture on user interface design1996).

16. Katre, D. S. A position paper on cross-cultural issues of bilingual (Hindi \& English) mobile phones. In Proceedings of the IndoDanish HCI Research Symposium (Guwahati, India, May 14-15, (2006). The Indian Institute of Technology Guwahati, Guwahati 781039. Assam India.

17. Gupta, R. Indian Language Support in Microsoft Products. 2004.http://tdil.mit.gov.in/Oct_2004/ILSMP-11.pdf 10 May 2010

18. Glamann, S. Mails uden $æ, \varnothing$ og å 2009.http://stenerg.blogspot.com/2009/01/mails-uden-og.html. Sunday, 17 May 2009

19. online, M. o. Document proofing tools. 2009.http://office.microsoft.com/enus/suites/FX101171811033.aspx Sunday, 17 May 2009

20. Andersen, A. Æ, Ø og Å på udanske computere De berejstes klub, 2005.http://www.berejst.dk/209/Tastatur.htm. Sunday, 17 May 2009

21. ICANN Guidelines for the Implementation of Internationalized Domain Names, Version 1.0, 20 June. 2003.http://www.icann.org/en/general/idn-guidelines20jun03.htm. Sunday, 17 May 2009

22. Speednames Domænenavne med æ, ø og å endelig klar til brug. 2003.http://www.verisign.com/static/002506.pdf. Sunday, 17 May 2009

23. Wenix Hvor er det latterligt at indfører sådan noget. 2003. http://newz.dk/ae-oe-og-aa-i-com-net-org-domaener. Sunday, 17 May 2009

24. Cole, M. and Cole, J. Re-fusing anthropology and psychology. In Bartlett, Culture \& Cognition Edited by A. Saito.Taylor \& Francis, 2000. 